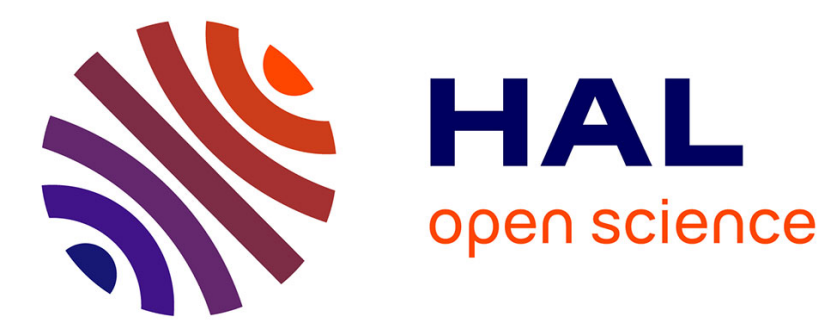

\title{
Development of a Simplified Approach for Using the Local Approach to Fracture
}

\author{
M. Di Fant, V. Le Coq, O. Cleizergues, G. Carollo, François Mudry, Laurent
}

Bauvineau, Hélène Burlet, André Pineau, Bernard Marini, M. Koundy, et al.

\section{- To cite this version:}

M. Di Fant, V. Le Coq, O. Cleizergues, G. Carollo, François Mudry, et al.. Development of a Simplified Approach for Using the Local Approach to Fracture. Journal de Physique IV Proceedings, 1996, 06 (C6), pp.C6-503-C6-512. 10.1051/jp4:1996650 . jpa-00254483

\section{HAL Id: jpa-00254483 https://hal.science/jpa-00254483}

Submitted on 1 Jan 1996

HAL is a multi-disciplinary open access archive for the deposit and dissemination of scientific research documents, whether they are published or not. The documents may come from teaching and research institutions in France or abroad, or from public or private research centers.
L'archive ouverte pluridisciplinaire HAL, est destinée au dépôt et à la diffusion de documents scientifiques de niveau recherche, publiés ou non, émanant des établissements d'enseignement et de recherche français ou étrangers, des laboratoires publics ou privés. 


\title{
Development of a Simplified Approach for Using the Local Approach to Fracture
}

M. di Fant, V. le Coq, O. Cleizergues, G. Carollo, F. Mudry, L. Bauvineau*, H. Burlet*, A. Pineau*, B. Marini**, M. Koundy**, C. Sainte Catherine** and C. Eripret***

IRSID, Voie Romaine, BP. 87, 57214 Maizières-les-Metz, France

* Centre des Matériaux P.M. Fourt, URA 866 du CNRS, BP. 87, 91003 Evry, France

** CEA, CE Saclay, 91191 Gif-sur-Yvette, France

***EDF, Centre de Recherche des Renardières, BP. 1, 77250 Moret-sur-Loing, France

\begin{abstract}
Today there is a strong demand from different industries to use local fracture criteria in a simplified way. This paper presents the main results of a two years joint research project where CEA, EDF, School of Mines and IRSID were associated. A simplified method based on the Beremin models for cleavage and ductile fracture has been developed. This procedure can be used to evaluate the risk of fracture of industrial structures or to allow a rapid development of new materials. Finite element simulations were systematically performed for axisymmetrically notched tensile and precracked specimens using a parametric description of stress-strain laws. Results were presented in the form of graphs that can be used directly for measuring local fracture parameters from tests on axisymmetrically notched specimens and to predict fracture toughness. An additional parameter measuring the level of plastic constraint has been taken into account. This parameter can be easily evaluated on industrial structures. This allows a simple way of using local criteria to evaluate the safety of such structures.
\end{abstract}

\section{INTRODUCTION}

Mainly as a requirement of the nuclear industry, local fracture criteria were developed to predict the failure of components by cleavage or ductile fracture. This research effort led to a methodology based on simple descriptions of the physical events leading to fracture and to the extensive use of numerical simulations for the assessment of structural integrity. This methodology is now well known and widely used $[1,2]$.

Today there is a strong demand from other industries to use such approaches in a simplified way. This is the reason why CEA, EDF, School of Mines and IRSID were associated in a two-years project with the aim of developing a simplified method based on the local fracture criteria in order to allow for:

- a rapid estimation of the risk of fracture of industrial structures,

- a rapid development of new materials and estimating their efficiency in real applications,

- an evaluation of fracture toughness properties from tests on small notched specimens,

- and to contribute to the development of numerical simulation techniques.

The aim of this paper is to present the main results of this project. Full details can be found elsewhere [3]. We begin with a brief description of the models that have been used. Then, finite element simulation results will be described for both round notched specimens and precracked specimens. They can directly be used for interpreting tensile tests on notched specimens and for making fracture toughness predictions. 


\section{BRIEF DESCRIPTION OF THE MODELS USED}

\subsection{Cleavage fracture}

In this study, the cleavage criterion proposed by Beremin [4] has been used. This criterion is based on two main features of the cleavage fracture mechanism in low carbon steels:

- The instability of existing microcracks in the material. This is described by the critical cleavage stress concept [5], taking into account the scatter of this value using the Weibull statistics.

- The need of plastic deformation for the initiation of microcracks in the material.

For an homogeneous material, a quantity called "Weibull stress" and denoted $\sigma_{\mathrm{w}}$ is introduced:

$$
\sigma_{w}=\sqrt[m]{\int_{P . Z} \sigma_{1}^{\mathrm{m}} \frac{d V}{V_{0}}}
$$

where $m$ is the exponent of Weibull's statistics, $V_{0}$ an arbitrary unit volume taken equal to $0.001 \mathrm{~mm}^{3}$ in this study and $\sigma_{1}$ the maximum principal stress. The integral is extended over the plastic zone because a local plastic deformation is needed to initiate microcracks.

The fracture probability $P_{\mathrm{r}}$ is then expressed as: $\left.P_{r}=1-\exp \left(-\frac{\sigma_{w}}{\sigma_{u}}\right)^{m}\right)$

where $\sigma_{u}$ is the critical cleavage stress for the elementary volume $V_{0}$.

\subsection{Ductile fracture}

The model proposed by Beremin for ductile fracture is very simple [6]. It is based on a direct integration of the cavity growth law proposed by Rice and Tracey [7]:

$$
\operatorname{Ln}\left(R / R_{0}\right)=\int_{\varepsilon_{d}}^{\varepsilon} 0.283 \exp \left(1.5 \frac{\sigma_{m}}{\sigma_{e q}}\right) d \varepsilon_{e q}
$$

where: $R_{0}$ is the initial diameter of a cavity, $R$ is the actual diameter of a cavity, $\varepsilon_{d}$ is the plastic deformation for cavity initiation (in this project we have assumed that this deformation is nul) and d $\varepsilon_{\mathrm{og}}$ corresponds to one increment of plastic deformation. The ductile fracture criterion is a critical value of $R / R_{0}$, denoted $\left(R_{R_{0}}\right) c$ and supposed to be a material characteristic.

\subsection{Method adopted}

The method adopted to simplify the use of the above models consisted of systematic calculations of round notched and precracked specimens. Results were presented in the form of graphs that can directly be used for interpreting tensile tests on round notched specimens and for predicting fracture toughness. In order to allow for the safety prediction of industrial components, an additional parameter measuring the level of plastic constraint has been considered. Each laboratory used its own finite element code: ASTER for EDF, CASTEM 2000 for CEA, ZEBULON-6 for school of Mines and IRSID. In a first step, a precise computation technique was defined and the results for one particular case were compared. Then, systematic parametric computations were performed.

\section{PARAMETRIC DESCRIPTION OF THE STRESS-STRAIN LAWS}

A parametric description of elastic-plastic stress-strain laws was needed. This preliminary work proved to be difficult since many constraints had to be fulfilled: 
- to be able to describe precisely a wide range of stress-strain laws usually encountered for metals and especially steels,

- to diminish as much as possible the number of independent parameters describing a given mechanical behaviour in order to limit the number of calculations to be performed,

- to stick as closely as possible to the laws used in test laboratories and generally implemented in finite element codes.

Finally, a very simple formula was chosen:

$$
\sigma=k \varepsilon_{t}^{n}=k\left(\sigma / E+\varepsilon_{p}\right)^{n}
$$

where $\sigma$ is the equivalent Von Mises stress, $\varepsilon_{t}$ is the total equivalent strain, $\varepsilon_{\mathrm{p}}$ is the plastic equivalent strain, $E$ is the Young's modulus ( $E=200 \mathrm{GPa}$ for all the calculations performed in this study), $R_{\odot}$ is the Yield strength, $\mathrm{k}$ is a parameter with a stress dimension, and $\mathrm{n}$ is a parameter without dimension usually called "strain hardening exponent".

It can readily be seen from this formula that the yield stress is a function of the two parameters $\mathrm{k}$ and $\mathrm{n}$ :

$$
R_{e}=k^{1 / 1-n} E^{-n / 1-n}
$$

The main advantage of this choice is that the stresses are related linearly to the parameter $\mathrm{k}$. Hence, the tables presenting the values of the Weibull stresses can be normalised by dividing all the stresses by $\mathrm{k}$. Finally, only one independent parameter, $\mathrm{n}$, remains which can be measured or estimated easily. In particular, if the true value of yield strength is not the one given in Table $1, \mathbf{k}_{1}$ may be chosen in such a way that: $R_{e}=k_{1}\left(R_{e} / E\right)^{n}$.

The following combinations of materials parameters were used in the project: $k=1000 \mathrm{MPa}$ and $n=0.01$; $0.05 ; 0.1 ; 0.15 ; 0.2 ; 0.3$. They cover the values usually found in steels. The values of yield strengths computed according to the formula (5) are given in table 1.

Table 1: Definition of the yield strength as function of the strain hardening exponent.

\begin{tabular}{|c|c|c|c|c|c|c|}
\hline $\mathbf{n}$ & 0.01 & 0.05 & 0.1 & 0.15 & 0.2 & 0.3 \\
\hline $\operatorname{Re}(\mathbf{M P a})$ & 948 & 757 & 555 & 393 & 266 & 103 \\
\hline
\end{tabular}

It is worth pointing out that Eq. (4) may be used in separate sections. For instance, the behaviour of many steels can be described in the form: $\sigma=k_{1} \varepsilon^{\mathrm{nl}}$ for $\varepsilon<\varepsilon_{0}$ and $\sigma=k_{2} \varepsilon^{\mathrm{n} 2}$ for $\varepsilon>\varepsilon_{0}$ with $\varepsilon_{0}$ given by $\mathrm{k}_{1} \varepsilon_{0}{ }^{\mathrm{nl}}=\mathrm{k}_{2} \varepsilon_{0}{ }^{\mathrm{n} 2}$. This behaviour will be called "piece-wise power law".

\section{ANALYSIS OF AXISYMMETRICALLY NOTCHED SPECIMENS}

\subsection{Computation technique}

Three geometries denoted AE10, AE4, AE2 were studied with notch radii respectively of 10,4 and $2 \mathrm{~mm}$. The geometry AE10 is shown in figure 1. The diameter of the minimal section is $10 \mathrm{~mm}$. One example of mesh is given in figure 2. Quadratic elements ( 8 nodes) with reduced integration (4 Gauss points) were used. Preliminary computations showed that the mesh size has to be lower than $500 \mu \mathrm{m}$ all along the section. The specimen is loaded by imposing a displacement on its upper side. All computations were performed using the small strain hypothesis with updating of the geometry between two increments. The stress-strain laws were introduced point by point in the finite element codes.

Two engineering parameters are usually used to describe the results: the mean strain, $\bar{\varepsilon}$, and mean stress, $\bar{\sigma}$, defined by: 


$$
\begin{aligned}
& \bar{\varepsilon}=2 \operatorname{Ln}\left(\Phi / \Phi_{0}\right) \\
& \bar{\sigma}=4 F / \pi \Phi^{2}
\end{aligned}
$$

where $\Phi_{\mathrm{O}}$ and $\Phi$ are the initial and actual diameters of the minimum section and $\mathrm{F}$ is the applied load.

The Weibull stresses are computed by adding the contributions element per element after averaging all the stress and strain components over the elements.

The value of the void growth ratio is evaluated according to the same technique. In this latter case, only the element corresponding to the center of the specimen where the stress triaxiality is the largest needed to be considered.

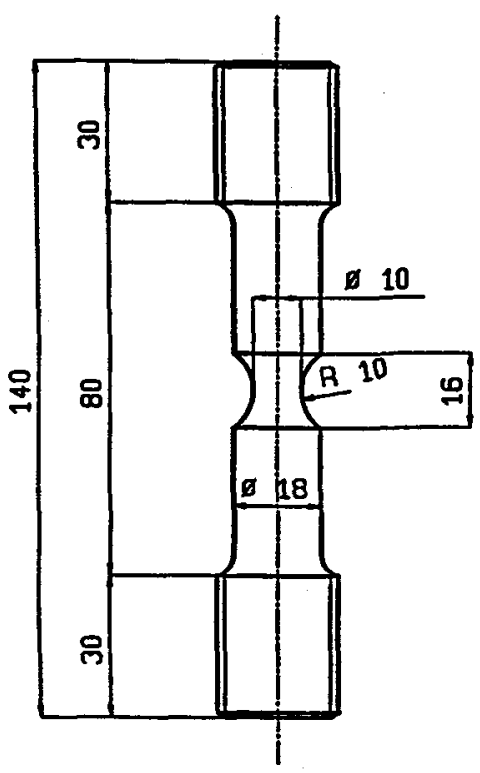

Figure 1: Geometry of the AE10 specimen.

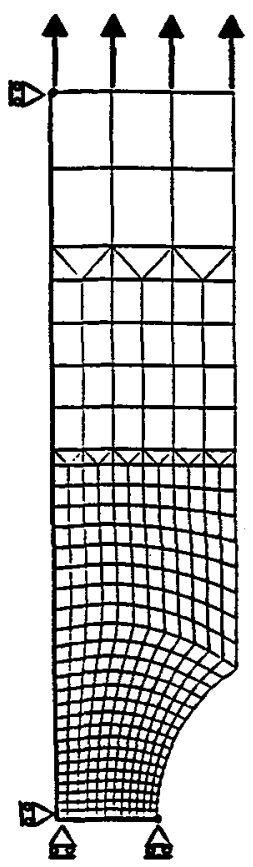

Figure 2: Mesh of the AE10 specimen.

\subsection{Tables for cleavage fracture}

The results were presented in the form of graphs. One table corresponds to a given geometry and a given value of $\mathrm{n}$. An example is shown in figure 3. Different curves giving $\sigma_{\mathrm{w}} / \mathrm{k}$ as function of the mean strain at fracture $\bar{\varepsilon}$ are presented. Each curve is associated to one value of the Weibull parameter, $m$. The values of $m$ vary from 8 to 40 with a step of 4 . The complete set of graphs can be found in the final report [3].

Comparisons of results obtained by the different participants in the small and large strain hypotheses may also be found in this report. The differences between laboratories remained below $4 \%$ for the $\sigma_{w}$ values. These differences were explained by differences in mesh sizes.

The local fracture parameters $\mathrm{m}$ and $\sigma_{\mathrm{u}}$ are determined with a set of experiments on round notched specimens as described in reference [8]. The main difficilty of this procedure is to compute the Weibull stress associated to each experiment.

The following procedure can now be used:

- measure the stress-strain law at the test temperature and determine $\mathrm{n}$ and $\mathrm{k}$, 
- perform the test on a given round notched specimen and measure the mean strain and mean stress at fracture,

- use different curves of the tables in order to determine by interpolation the Weibull stress corresponding to the same value of $\mathrm{m}, \mathrm{n}$ and $\mathrm{k}$,

- if the minimum diameter, $\Phi_{0}$, is different from $10 \mathrm{~mm}$, multiply the value of the Table by

$$
\left(\Phi_{0} / 10 \mathrm{~mm}\right)^{(3 / \mathrm{m})}
$$

A similar procedure is described in the final report [3] for the "piece-wise power law" behaviour described in $\S 3$.

\subsection{Tables for ductile fracture}

An example of such a graph is given in figure 4 . The cavity growth ratio is given as a function of the mean strain at fracture for different strain hardening exponents. The complete set of graphs can be found in the final report [3]. For one experiment, the determination of the critical void growth ratio results directly from an interpolation between two curves of the corresponding table.

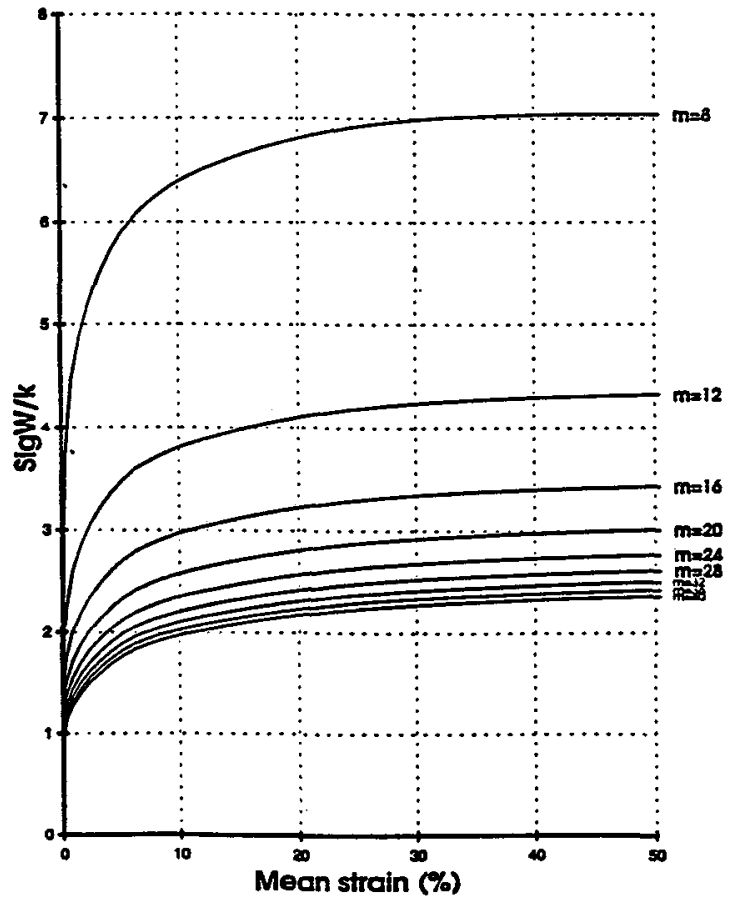

Figure 3: Example of graph for cleavage fracture. geometry AE2. $n=0.1$.

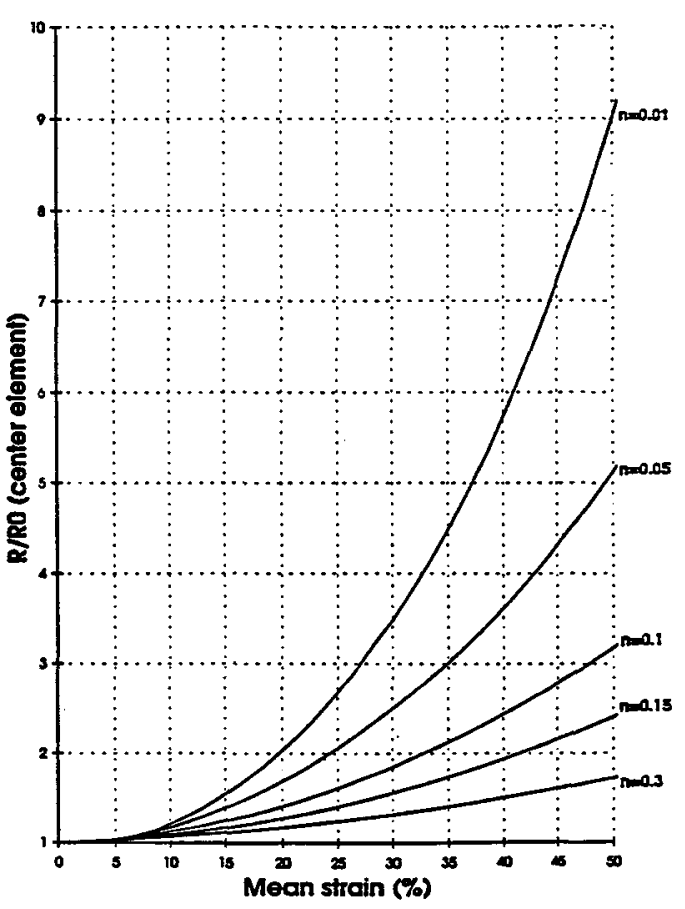

Figure 4: Example of graph for ductile fracture. geometry AE2 


\section{ANALYSIS OF PRECRACKED SPECIMENS}

\subsection{Choice of different specimen geometries-Constraint effects}

The stress intensity factor, $\mathrm{K}$, the $\mathrm{J}$ integral and the Crack Tip Opening Displacement, CTOD, are the most commonly used parameters in fracture mechanics. In the case of constrained plasticity and a high level of stress triaxiality, these load-geometry parameters describe the local stresses and strains at a crack tip. A certain number of recent studies have shown that these parameters need to be associated to a second parameter measuring the plastic constraint level. The parameter, $T$, was initially introduced by Williams [9] and more recently by Hancock [10-11]. It is defined for an elastic material and corresponds to a stress parallel to the crack plane:

$$
\sigma_{i j}=\frac{K_{I}}{\sqrt{2 \cdot \pi \cdot r}} f_{i j}(\theta)+T \delta_{x i} \delta_{x j}+0(\sqrt{r})
$$

where $K_{1}$ is thestress intensity factor, $f_{i j}(\theta)$ is a function independent of the geometry and loading, $r, \theta$ are conventional polar coordinate system ahead of the crack tip and $\mathrm{x}$ is the direction of crack propagation.

In order to cover a wide range of $\mathrm{T}$ values, 5 specimens' geometries were chosen (see figure 5 )

- Compact tension specimen " $\mathrm{CT}$ " with $\mathrm{a} / \mathrm{W}=0.5$

- Three point bend specimen "3PB" with $\mathrm{a} / \mathrm{W}=0.5$

- Three point bend specimen "3PB" with $\mathrm{a} / \mathrm{W}=0.39$

- Three point bend specimen "3PB" with $\mathrm{a} / \mathrm{W}=0.1$

- Center crack panel specimen "CCP" with a/W=0.5

The two first specimens are usually used for fracture toughness measurements. Table 2 gives for each geometry the calculates values of the normalised parameter defined by:

$$
\mathrm{B}=\frac{\mathrm{T} \sqrt{\pi \cdot \mathrm{a}}}{\mathrm{K}_{\mathrm{I}}}
$$

Table 2 : Values of the parameter B calculated for different specimens geometries

\begin{tabular}{|c|c|c|c|c|c|}
\hline Specimen & $\mathrm{CT} \mathrm{a} / \mathrm{W}=0.5$ & $3 \mathrm{~PB} \mathrm{a} / \mathrm{W}=0.5$ & $3 \mathrm{~PB}$ a/W=0.39 & $3 \mathrm{~PB}$ a $/ \mathrm{W}=0.1$ & $\mathrm{CCP} \mathrm{a} / \mathrm{W}=0.5$ \\
\hline $\mathrm{B}$ & 0.59 & 0.14 & -0.01 & -0.36 & -1.05 \\
\hline
\end{tabular}

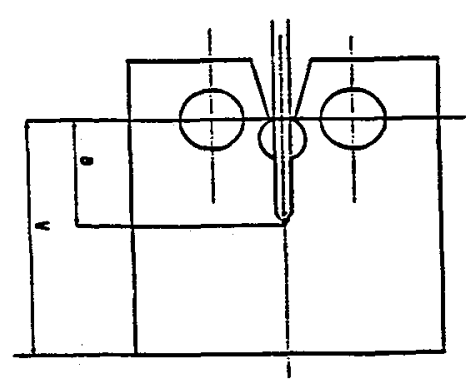

CT

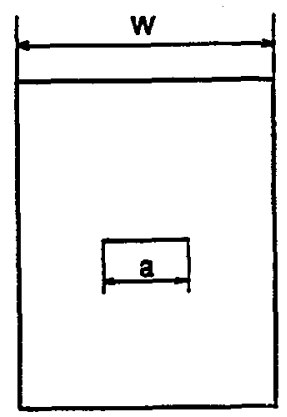

CCP

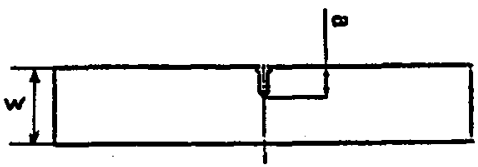

3PB

Figure 5: Geometries of the precracked specimens. 


\subsection{Tables for cleavage fracture}

\subsubsection{Computation technique}

For an elastic-plastic material, the HRR field [12-13] predicts a strain singularity at the crack tip. In the case of perfect plasticity, this singularity varies as $1 / r$. Taking into account the crack blunting phenomenon (i.e. a finite value of the curvature radius at the crack tip, $\rho=C T O D / 2$ ), Rice and Johnson [14] found that the strain field varies as $\ln (r / \rho)$.

Starting from these theoretical results, it appears that a mesh size smaller than $\rho$ is needed in a finite element simulation in order to describe correctly the local stress concentration at the crack tip. The strains in the first mesh with a size, $d$, will be of the order of $\mathrm{r} / \mathrm{d}$. This corresponds to several thousands of percents. Such levels of deformation cannot be treated easily with conventional finite element codes. Moreover, the measurement of stress-strain laws is usually limited to the occurrence of necking in a tensile test (around 15\%) and needs to be extrapolated to higher strains.

In order to overcome this difficulty, Mc. Meeking [15] proposed to introduce an initial blunting of the crack in the mesh. He showed that, when the actual blunting overcomes the initial imposed value, CTODi, the stress profiles are the same as for a sharp crack. Consequently, this computing procedure was chosen in the project.

An example of mesh for the CT specimen is shown in figure 6.
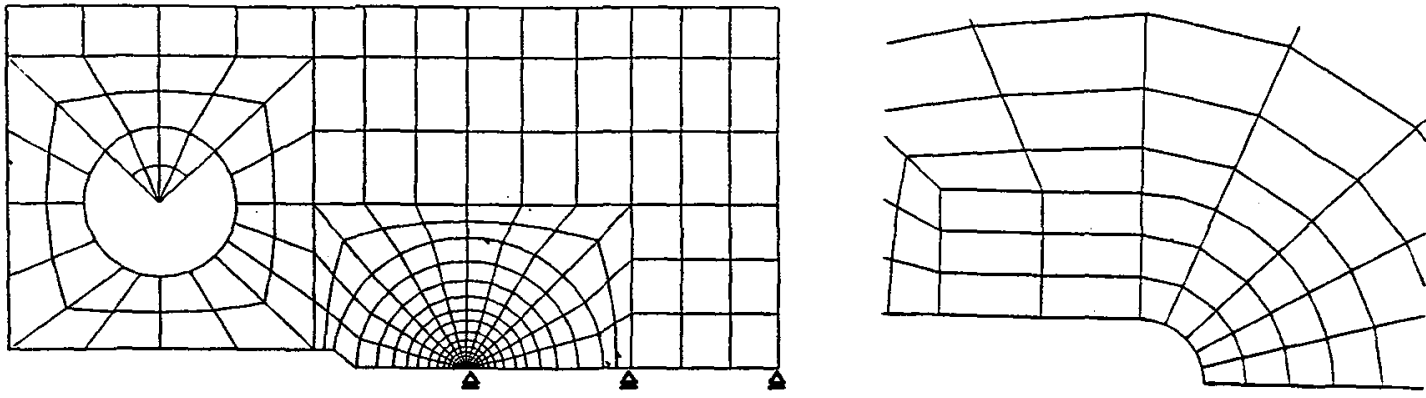

Figure 6: Mesh used for the CT specimen geometry.

All meshes were made for a value of $W=50 \mathrm{~mm}$. Quadratic plane strain elements ( 8 nodes) with reduced integration (4 Gauss points) were used. To compute the values of CTOD, the formula proposed by Mc Meeking [15] was used:

$$
C T O D=\frac{0.6 K^{2}}{E R_{e}}\left[\frac{2(1+v)(1+n)}{\sqrt{3}} \frac{R_{e}}{n E}\right]^{n}
$$

where $\mathrm{n}$ is the strain hardening exponent, $v=0.3$ the Poisson coefficient and $\mathrm{E}$ the Young's modulus.

The value of $C T O D_{i}$ was chosen to be approximately equal to CTOD ${ }_{\max } / 3$, where CTOD $_{\max }$ is the value of the crack tip blunting at the limit load of the specimen. Table 3 summarises the initial blunting radii associated to each value of $n$. Clearly the computations with $n=0.3$ require very small meshes.

All computations were performed for the small strain hypothesis with updating of the geometry between two increments. The stress-strain laws were introduced point by point in the finite element codes.

The $J$ value was computed with the contour integral technique. CTOD values were determined with the formula given in the ASTM E-1290 and AFNOR A03-182 standards. 
Table 3: Initial blunting values used for the mesh construction

\begin{tabular}{|c|c|c|c|c|}
\hline $\bar{n}$ & $\operatorname{Re}(\mathbf{M P a})$ & $\begin{array}{c}\text { CTOD }^{*} E^{*} \operatorname{Re} / K^{\wedge} 2 \\
\text { Mc Meeking }\end{array}$ & $\begin{array}{l}\text { CTOD }_{\max } \\
(\mu \mathrm{m})\end{array}$ & $\begin{array}{l}\text { Initial blunting radius } \\
(\mathrm{CTODi} / 2)(\mu \mathrm{m})\end{array}$ \\
\hline 0.01 & 948 & 0.499 & 47 & 8 \\
\hline 0.05 & 757 & 0.450 & 34 & 6 \\
\hline 0.1 & 555 & 0.368 & 20 & 3 \\
\hline 0.15 & 393 & 0.284 & 11 & 2 \\
\hline 0.2 & 266 & 0.207 & 5.5 & 1 \\
\hline 0.3 & 103 & 0.0906 & 0.93 & 0.15 \\
\hline
\end{tabular}

It should be noted that for the usual values of $\mathrm{m}$ around 20 , the value of the Weibull stress is controlled mainly by the value of the maximum stress in the specimen. Preliminary computations showed that the values of the Weibull stresses were independent on the mesh size for values of $n$ below 0.15 . This is mainly due to the fact that the maximum value of the stress lies ahead of the blunted crack. This is no longer the case for values of $n$ above 0.15 . No simple solution was found to overcome this difficulty in a simple way and the computations for $\mathrm{n}=0.2$ and 0.3 were thus not performed.

As for the round notched specimens, the Weibull stresses are computed by adding the contributions of each element after averaging all the stress and strain components over the elements. Calculations aimed at studying the effect of the mesh size, showed that a value equal to the initial notch radius ahead of the blunted crack tip is sufficiently small.

\subsubsection{Presentation of the results}

Starting from the HRR stress profile, Beremin [4] established the following relation:

$$
\sigma_{w}{ }^{m}=\frac{K^{4} B \mathrm{Re}^{m-4} \mathrm{Cm}}{V_{0}}
$$

where $B$ is the thickness of the specimen, $V_{0}$ an elementary volume and $\mathrm{Cm}$ a constant dependent on $\mathrm{m}$ and $\mathrm{n}$. The presentation of the finite element results was drawn from this formula. The value of $\mathrm{m}^{*} \ln \left(\sigma_{\mathrm{w}} / \mathrm{k}\right)$ is given as function of $\ln (\mathrm{J} / \mathrm{k})$ or $\ln$ (CTOD). An example of such a graph developed is given in figure 7 for the CT specimen and $n=0.1$. The different curves correspond to values of the Weibull modulus as a function of the loading parameter. The two vertical lines indicate the point where the value of CTOD (doted line) computed with formula (10) is equal to the initial value of the CTOD and the point where the limit load of the specimen is reached.

Full details concerning the complete set of tables and their use may be found in reference [3].

The general procedure is the following:

- starting from a probability of fracture, $P_{\mathrm{r}}$, and from the knowledge of the local fracture parameters $m$ and $\sigma_{u}$, use formula (2) to compute a value of $\sigma_{\mathrm{w}}$,

- make a correction in order to get the value of $\sigma_{\mathrm{w}}$ for $\mathrm{B}_{0}=1 \mathrm{~mm}$ :

$$
\sigma_{\mathrm{wc}}=\sigma_{\mathrm{w}}\left(\mathrm{B}_{0} / \mathrm{B}\right)^{(1 / \mathrm{m})}
$$

- use the tables to determine the values of CTOD or J associated to $P_{r}$.

In the case of the assessment of a structure, the $T$ factor should be estimated first in order to find the most representative specimen geometry computed in this project.

\subsection{Tables for ductile fracture}

For ductile fracture, the mesh size at the crack tip, $\Delta \mathrm{a}$, is considered as a material constant representative of the mean spacing between inclusions. Ductile fracture occurs as soon as the critical void growth ratio is 
reached in the element at the crack tip. In this project, finite element simulations were performed only with one value of $\Delta \mathrm{a}, 200 \mu \mathrm{m}$. Graphs were presented in the form of curves giving $\Delta \mathrm{a} \cdot \ln (\mathrm{R} / \mathrm{Ro})$ as a function of $\mathrm{J} / \mathrm{Re}$ for different values of $\mathrm{n}$. The interested reader is referred to reference [3] for further details.

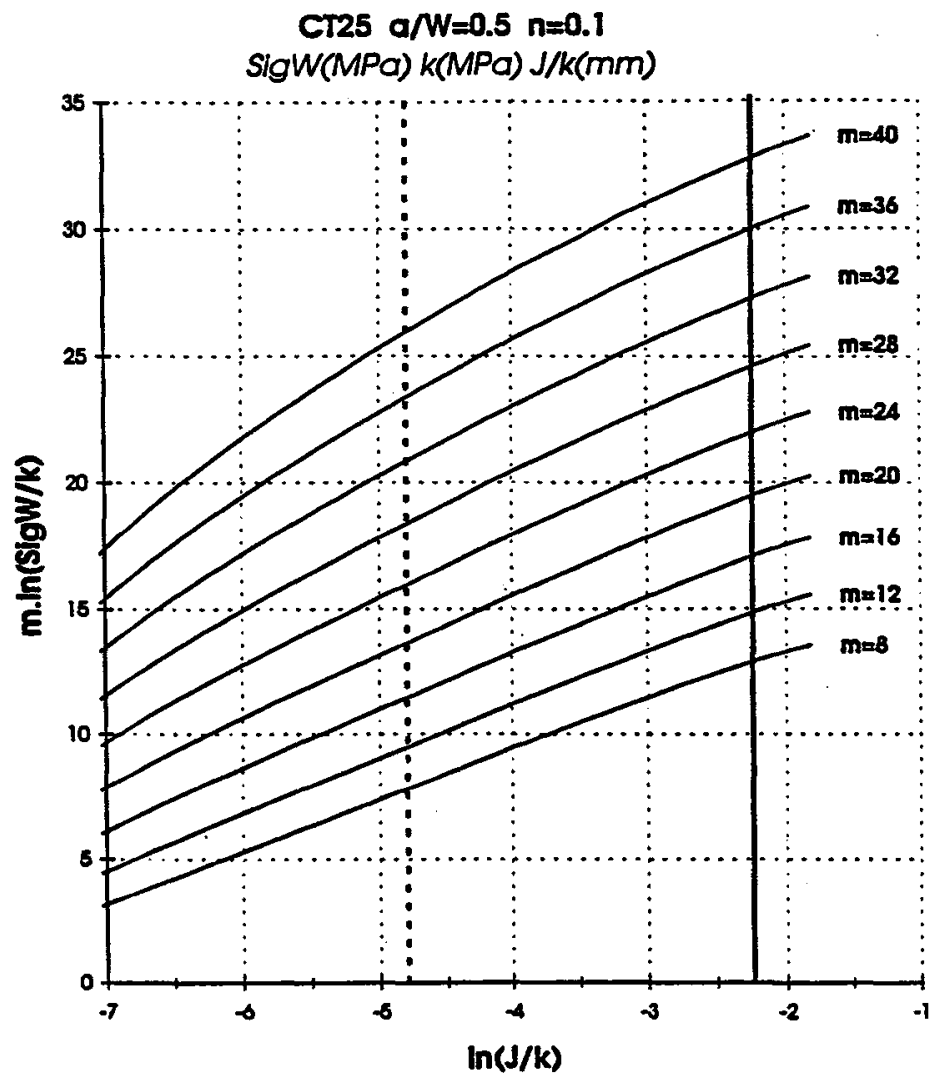

$\cdots \mathrm{COD}=\mathrm{CODI}-$ Charge limite

Figure 7: Example of graph for cleavage fracture $-C T$ geometry $n=0.1$

\section{CONCLUSIONS}

A simplified methodology for using the Beremin models for cleavage and ductile fracture has been developed. Finite element simulations were performed in a systematic way for both axisymmetrically notched tensile and precracked specimens using a parametric description of stress-strain laws. Results were presented in the form of graphs that be can directly used to measure local fracture parameters with tests on axisymmetrically notched specimens or to predict fracture toughness or CTOD values. In order to apply these tables to evaluate the safety of industrial structures, an additional parameter measuring the level of plastic constraint has been taken into account. 
Through the numerous exchanges of experience between the four laboratories involved in this work, a common methodology was found. From this point of view, the results obtained may be considered as a contribution to the standardisation in the field of local approach models.

This effort of simplification will now be followed in different directions:

- extension of the graphs for ductile fracture to other values of the mean spacing between inclusions,

- application of the methodology for heterogeneous materials such as welded joints,

use of the Charpy test instead of axisymmetrically notched tensile specimens in order to simplify further the experimental work.

\section{ACKNOWLEDGMENTS}

Financial support by the French "Ministère de la Recherche et de l'Enseignement Supérieur" is gratefully acknowledged.

\section{REFERENCES}

[1] Mudry, F., Di Fant, M., "A Round Robin on the measurement of local criteria", Report IRSID RE 93319, October 1993.

[2] Proceedings of an ASME Conference "Advances in local fracture/damage models for the analysis of engineering problems", Tempe, Arizona, April 28-May 11992.

[3] Di Fant, M., Le Coq, V., Cleizergues, O., Carollo, G., Mudry, F., Bauvineau, L., Burlet, H., Pineau, A., Marini, B., Koundy, M., Sainte Catherine, C., Eripret, C., "Mise en place d'une méthodologie simplifiée pour utiliser des critères locaux de rupture", Rapport final, Convention MRES $n^{\circ}$ 92.A.0334, IRSID RE 96.03, Février 1996.

[4] Beremin, F.M., "A local criterion for cleavage fracture of a nuclear pressure vessel steel", Met. Trans. 14A, 1983, pp. 2277-2287.

[5] Knott, J.F., "Micro-mechanisms of fracture and the fracture toughness of engineering alloys", 4th. Int. Conf. on Fracture, Canada 1977, vol. 1, pp.61-92.

[6] Beremin, F.M., "Experimental and numerical study of the different stages in ductile rupture: application to crack initiation and stable crack growth", in Three Dimensional Constitutive Relations and Ductile Fracture, Ed. Nemat Nasser, 1981, PP. 185-205.

[7] Rice, J.R., Tracey, D.M., "On the ductile enlargement of voids in triaxial stress fields", J. Mech. Phys. Solids, vol.17, 1969, pp.201-217.

[8] ESIS, " Draft procedure to measure and calculate Local Approach Criteria using notched tensile specimens", ESIS P6-94 D, version 3.0, November 1995.

[9] Williams, M.B., "On the stress distribution at the base of a stationary crack", Journal of Applied Mechanics, Vol. 24, 1957, pp. 109-114.

[10] Betegon, C., Hancock, J.W., J. W. 'Two parameter characterization of elastic-plastic crack tip fields.', Journal of Applied Mechanics, Vol. 58, 1991, pp. 104-110.

[11] Al Ani, A. A., Hancock, J.W., "J-dominance of short cracks in tension and bending", Journal of the Mechanics and Physics of Solids, Vol. 39, 1991, pp. 23-34.

[12] Hutchinson, J. W., "Singular behavior at the end of a tensile crack in a hardening material.", Journal of the Mechanics and Physics of Solids, Vol. 16, 1968, pp. 13-31.

[13] Rice, J. R., Rosengreen, G. F, "Plane strain deformation near a crack tip in a power law hardening material.", Journal of the Mechanics and Physics of Solids, Vol. 16, 1968, pp. 1-12.

[14] Rice, J.R., Johnson, M.A., "The role of large crack tip geometry changes in plane strain fracture", Inelastic Behaviour of Materials, Ed. Kanninen, McGraw-Hill, 1970, p.641.

[15] Mc Meeking, R.M., "Finite deformation analysis of crack-tip opening in elastic-plastic materials and implications for fracture", Journal of the Mechanics and Physics of Solids, Vol. 25, 1977, pp. 357381. 